\title{
Trends in mortality from diabetes mellitus in Taiwan, 1960-1988
}

\author{
R.S.Lin and W.C. Lee \\ Institute of Public Heaith, College of Medicine, National Taiwan University, Taipei, Taiwan
}

\begin{abstract}
Summary. The increasing trends of mortality from diabetes mellitus in Taiwan are becoming a public health concern. The age-adjusted death rate for diabetes was 3.7 per 100,000 population in 1960 , which increased to 23.2 per 100,000 in 1988 , a 6.3 -fold increase over the past 30 years. The mortality data for diabetes in Taiwan from 1960 to 1988 for both sexes are presented and analysed using an age-period-cohort model in order to gain a better understanding of the possible determinants of the time trends of this disease. Steeply increasing trends which are particularly prominent in the elder-
\end{abstract}

ly are found in the periods studied. Females and urban dwellers demonstrated greater risks for developing the disease. Significant cohort effects were found which peaked in the birth-cohort 1910-1917. This declined thereafter for females but has levelled since then for males. Further study is necessary to assess the aetiological implications of diet and urbanization on time trends of diabetes.

Key words: Diabetes mellitus, mortality trends, age-periodcohort analysis, urbanization.
Over the past 30 years, Taiwan has experienced a rapid socioeconomic development that is reflected in changes of many aspects of life-style and dietary habits and to a large extent also in disease patterns. Chronic diseases, e.g. cerebral and cardiovascular diseases and diabetes mellitus have emerged as major diseases threatening the lives of the inhabitants on this island. While the leading cause of death was previously cerebrovascular disease, cancer has been responsible for most deaths since 1982. However, the most remarkable increase in chronic disease mortality in the past 30 years has been due to diabetes. In 1960 , diabetes was responsible for less than $0.3 \%$ of total deaths, while this figure increased remarkably to $3.8 \%$, accounting for more than 3,800 deaths in 1988. Diabetes is now the fifth leading cause of death in Taiwan next to cancer, cerebrovascular disease, accident and coronary heart disease (Table 1).

In addition to being a significant cause of mortality, diabetes is believed to be a major cause of disability in the elderly including blindness, renal failure, and lower limb amputations. Cardiovascular and peripheral vascular conditions appear to be about two times as common in diabetic patients as in non-diabetic subjects [1]. Diabetes clearly represents an important public health problem in Taiwan as well as in other developed countries. Although it is well-known that genetic factors are involved in the aetiology of diabetes, the tremendous increase in diabetic mor- tality in Taiwan over the past 20 years denotes the fact that environmental factors play an important role in the causation of Type 2 (non-insulin-dependent) diabetes. In this study, mortality data from diabetes in Taiwan were analysed and presented in order to better understand the way dietary as well as urbanizational factors affect the secular trends.

\section{Subjects and methods}

\section{Subjects}

Information on diabetes mortality and the data of mid-year population in Taiwan from 1960 to 1970 were taken from the "Vital statistics" published annually by the Taiwan Provincial Department of

Table 1. Number of deaths from diabetes mellitus in Taiwan, 19601988 , by year

\begin{tabular}{lcll}
\hline Year & $\begin{array}{l}\text { Number of } \\
\text { diabetes deaths }\end{array}$ & $\begin{array}{l}\text { Proportion of } \\
\text { total deaths }(\%)\end{array}$ & $\begin{array}{l}\text { Order in leading } \\
\text { causes of death }\end{array}$ \\
\hline 1960 & 198 & 0.27 & 29 \\
1970 & 482 & 0.71 & 18 \\
1980 & 1,396 & 1.67 & 13 \\
1985 & 2,930 & 3.22 & 7 \\
1988 & 3,883 & 3.84 & 5 \\
\hline
\end{tabular}




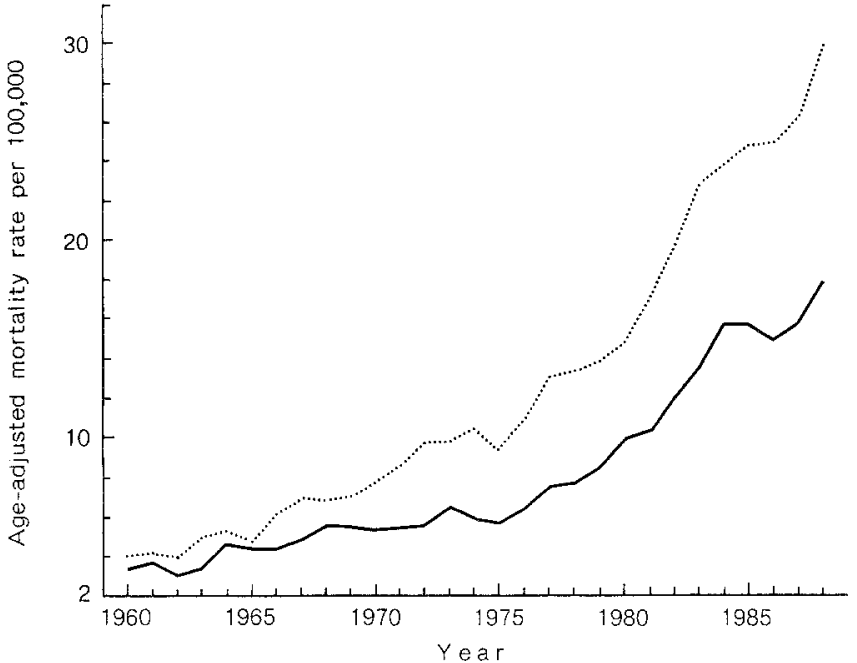

Fig. 1. Trends of diabetes mellitus mortality in Taiwan, 1960-1988, by sex. Male-, Female .....

Health, R. O.C. [2] where they were tabulated by sex and 5-year age group. The individual health records of all reported cases as well as population data for each township and district in Taiwan between 1971 and 1988 were generated directly from computerized government data sets. The contributing causes of death were not available in either the annual report or the computer file. Thus, mortality from diabetes, in this study, was defined as code number 250 in both International Classification of Diseases (ICD)-8 and (ICD) -9 listed in the death certificates as the underlying cause of death.

The degree of urbanization of each township and district in Taiwan was given an index of 1 to 8 in the study of urban-rural classification by Tzeng and Wu [3], in which variables of population density, age composition, mobility, economic activity and family income, educational level, and health and sanitation facilities were used to estimate the urbanization score. Metropolitan areas, in this study, are defined as those with index 1-2, and cities, index $3-4$, towns, index $5-6$, and rural areas, index $7-8$, respectively.

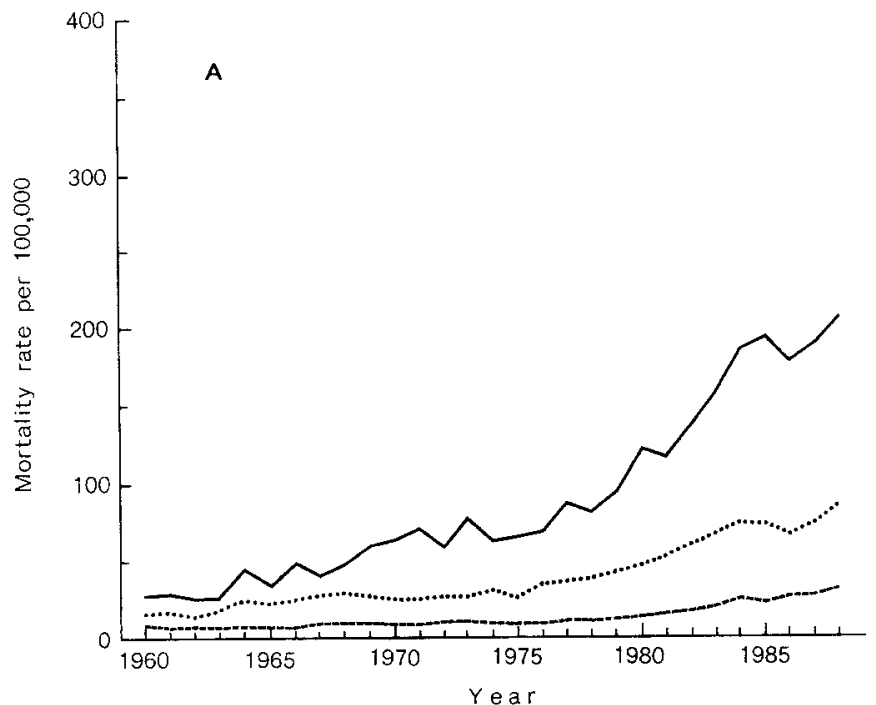

Data of annual per capita income and of calorie, protein, and fat consumption in Taiwan between 1960 and 1988 were taken from "Taiwan Statistical Data Book" published by the Council for Economic Planning and Development, R.O.C. [4].

\section{Statistical analysis}

In order to minimize the effect of different age compositions for different periods and different areas, the secular trends of diabetes mortality rates for the whole population between 1960 and 1988 and the trends of diabetes mortality rates by urbanization in Taiwan were age-adjusted [5] to the 1976 world standard population [6].

The statistical age-period-cohort analysis (APC Model), which adopted the "individual record" method of Robertson and Boyle [7] to circumvent the problem of non-identifiability, was performed using the data between 1971 and 1988.

The mortality of diabetes mellitus in a particular group (age-period-cohort) is assumed to follow a Poisson distribution, with a mean $\mu=N \cdot r$, where $N$ is person-years at risk in a particular group, and $r$ is the mortality rate from diabetes in that group. The mortality rate $r$ is modelled as a log-linear function of age, period and cohort separately for males and females. The baseline groups are ages $40-44$, calendar year 1971-1973, and birth year 1887-1893 for age, period, and cohort factors, respectively. The maximum likelihood estimation was used to fit the models through the statistical package Egret [8]. The significance of the factors (age, period, and cohort), were assessed by means of a likelihood ratio test. Other methodological details can be found elsewhere [9].

\section{Results}

Figure 1 shows the trends for age-adjusted mortality rates of diabetes for males and females in Taiwan between 1960 and 1988 . The increasing trends in mortality rates from diabetes are large. For males, the annual age-adjusted mortality rate increased from 3.32 per 100,000 population in 1960 to 17.84 per 100,000 population in 1988 , a 5.4-fold increase, and for females, 4.05 per 100,000 population in 1960 to 30.01 per 100,000 in 1988 , a 7.4-fold increase. The secular trends in Figure 1 also show that the increases in

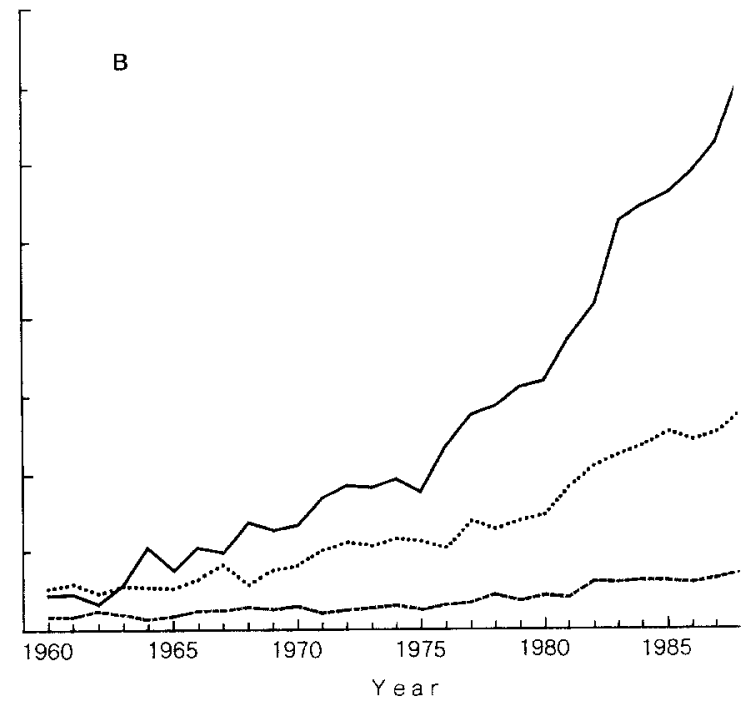

Fig. 2A, B. Secular trends of age-specific mortality from diabetes mellitus in Taiwan, 1960-1988, by sex. A Male 70+- $60-69 \ldots \ldots, 50-59---$ B Female $70+-, 60-69 \ldots, 50-59 \ldots$. 


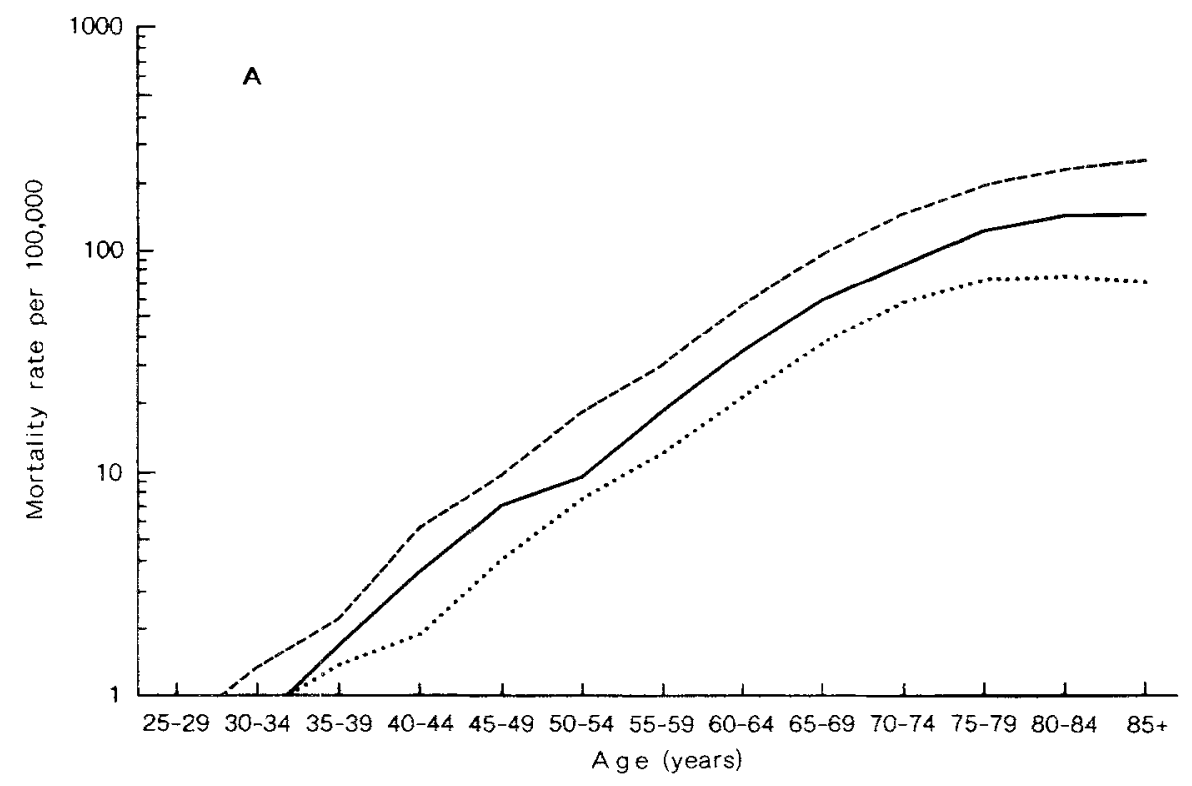

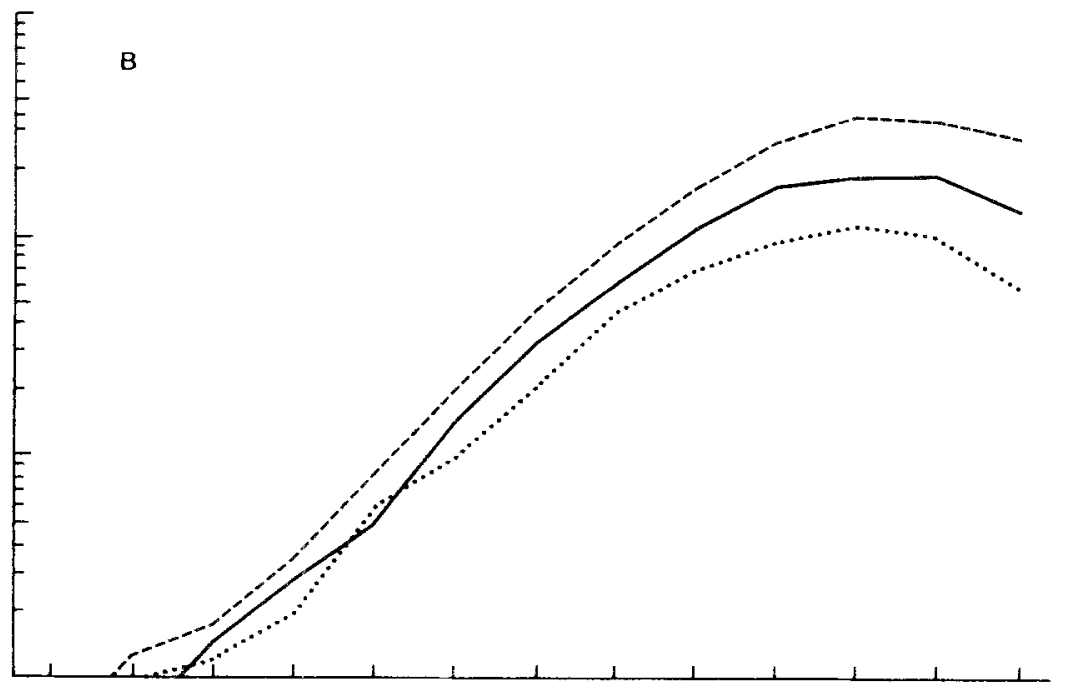

25-29 $30-34 \quad 35-39 \quad 40-44 \quad 45-49 \quad 50-54 \quad 55-59 \quad 60-64 \quad 65-69 \quad 70-74 \quad 75-79 \quad 80-84 \quad 85 \div$ Age (years)
Fig. 3 A, B. Age-specific mortality rate from diabetes mellitus in Taiwan, for the periods of 1971 1976, 1977-1982 and 1983-1988, by sex. A Male 1983-1988 - -, 1977-1982-, 1971-1976 … B Female 1983-1988 -.-, 1977-1982-, 1971-1976 … Mortality rate is expressed on a logarithmic scale mortality from diabetes were particulary remarkable in the last 10 years for both sexes.

Further analysis of the age-specific mortality rates of three different age groups were plotted in Figure 2 for males and females. It can be seen that the oldest age group of 70 and over in both sexes showed the most dramatic secular trends, especially females (15.8-fold increase).

Depicted in Figure 3 are the cross-sectional age distributions of mortality from diabetes for three consecutive periods of 1971-1976, 1977-1982 and 1983-1988 for both sexes. It can be seen that the mortality rates increased progressively with age for males but showed a downward curvature after age 75 years for females.

The separate effects due to age, cohort and period indices, respectively (Fig. 4-6) were estimated from the APC model [7] and were all statistically significant $(p<0.01)$ as judged by the likelihood ratio test (Table 2$)$. The oldest age group, (80-84 years) had 46.8 and 60.1 times the risk of dying from diabetes as compared to the youngest age group of 40-44 years for males and females, respectively. The downward curvature after ages 75 years for females observed in the cross-sectional age distributions (Fig. 3) disappeared in this birth-cohort analysis (Fig. 4). As regards cohort effects, females born between 1910-1917 achieved the highest risk among the birth cohorts studied (the relative risk is 2.04 as compared to the 1887-1893 birth cohort) and the effect declined in the recent cohorts. For males, the birth-cohort effect was less conspicuous. It was increasing before the year 1909 , reached a peak in 1910-1917 and remained at about the same level of risk thereafter (1.5 times the risk as compared to the $1887-1893$ birth cohort). We also analysed the cohort effects using finer grouping in the age, period, cohort indices and the results were essentially the same.

The age-adjusted diabetes mortality rates by the degree of urbanization between 1971-1988 for males and fe- 


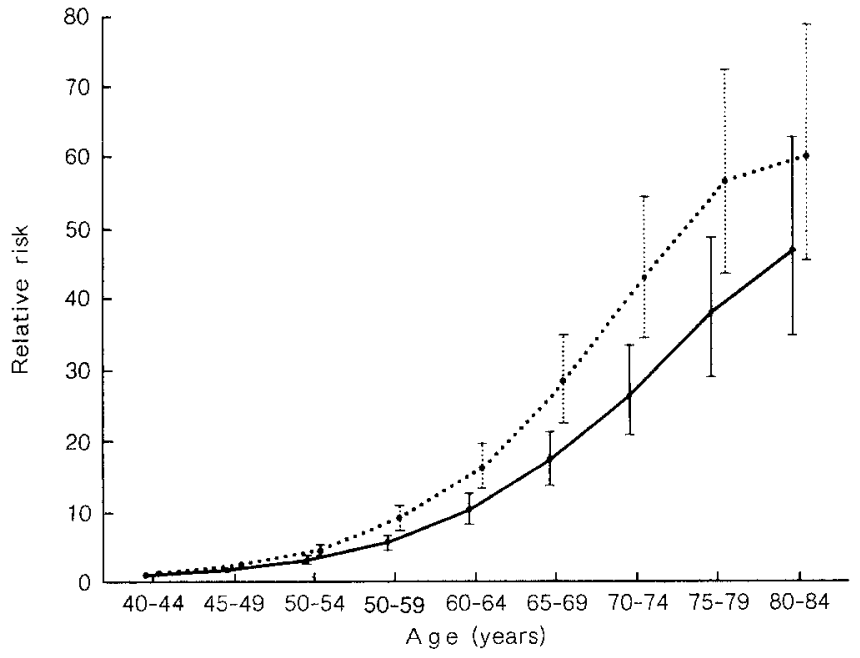

Fig.4. Age effect (with $95 \%$ confidence interval) in diabetes mellitus mortality in Taiwan, 1971-1988, by sex. Male •- $\longrightarrow$, Female $\bullet \cdot \cdots \cdot \bullet$.

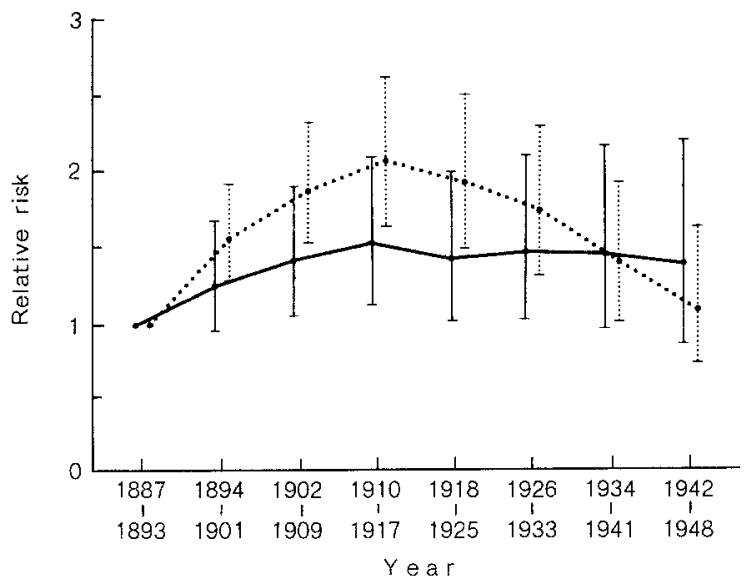

Fig. 5. Cohort effect (with $95 \%$ confidence interval) in diabetes mellitus mortality among birth cohorts of 1887-1948 in Taiwan, by sex. Male $\bullet-\bullet$ Female $\bullet \cdots \cdot \bullet$.

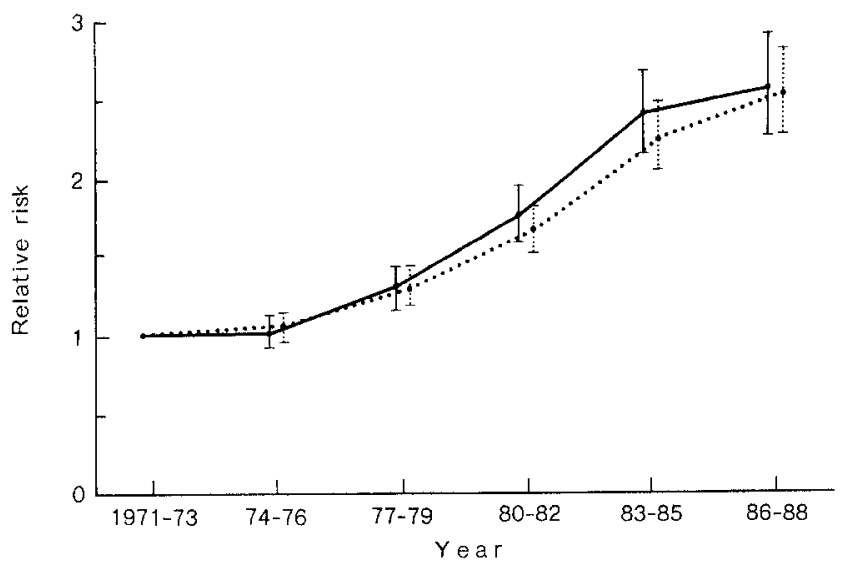

Fig.6. Period effect (with $95 \%$ confidence interval) in diabetes mellitus mortality in Taiwan, 1971-1988, by sex. Male $\bullet-\bullet$, Female $\bullet \cdot . . . \bullet$.

males are presented in Figure 7. Generally, metropolitan residents had a 1.5 -fold higher diabetes mortality rate than those in rural areas. The comparisons of time trends for diabetes mortality rates by urbanization also revealed that residents in rural areas will reach diabetes mortality rates as high as the metropolitan figures in about 6 years.

Figure 8 shows the trends of annual per capita income and of calorie, protein, and fat consumption in Taiwan between 1960 and 1988. The increasing trends of fat consumption and calorie intake seem very similar to the trends of diabetes mortality (Pearson correlation coefficients, 0.97 and 0.82 , respectively).

\section{Discussion}

In the absence of comprehensive incidence and prevalence data about diabetes, studies based upon vital statistics compiled from death certificates seemed a reasonable first step in estimating trends of diabetic risk. However, several studies have demonstrated that diabetes was reported as the underlying cause in only about $7 \%$ and as a contributing or "other" cause in about one-third of all death certificates [10-12]. Underestimation of mortality rates from diabetes was, therefore, inevitable, if vital statistic data were used. It should be kept in mind that even in complete ascertainment from death certificates, from both underlying and contributing causes, using mortality data to study trends in diabetes had the drawback of separating the effects of improvement in medical care accessibility and the reduction in case fatality rate due to better treatment from true incidence change. Thus, studies based upon vital statistics give only an imprecise picture of trends in diabetes.

The dramatic increase in mortality from diabetes in Taiwan between 1960 and 1988 as revealed in our study, did, however, provide some clues about the risk factors for the disease. It was unlikely that improved case ascertainment or better diagnosis from the improvement in medical care facilities account for all of the increases, When these trends did occur, they often started at a younger age, and shifted to the elderly. However, our observations show that the mortality rates in the young are stable, while those in the elderly increase dramatically. The results of the prevalence survey of diabetes conducted in Taipei City (the largest city in Taiwan) which also

Table 2. Variable selection in age-period-cohort models of diabetes mellitus mortality in Taiwan, 1971-1988

\begin{tabular}{lrrr}
\hline Model & $d f$ & Deviance & $\begin{array}{l}\text { Likelihood } \\
\text { ratio } \\
\text { statistic }(d f)^{\mathrm{a}}\end{array}$ \\
\hline Male & 85 & 1713.7 & $14764.6(8)^{\mathrm{b}}$ \\
$\quad$ Age & 80 & 104.9 & $1608.8(5)^{\mathrm{b}}$ \\
Age, period & 73 & 84.6 & $20.3(7)^{\mathrm{b}}$ \\
Age, period, cohort & & & \\
Female & 85 & 2401.9 & $25047.8(8)^{\mathrm{b}}$ \\
Age & 80 & 238.7 & $2163.0(5)^{\mathrm{b}}$ \\
Age, period & 73 & 114.7 & $123.9(7)^{\mathrm{b}}$ \\
Age, period, cohort & & &
\end{tabular}

a Each likelihood ratio statistic refers to the last term entered into the model and has an approximate chi-square distribution with the appropriate degree of freedom $(d f)$.

${ }^{\mathrm{b}} p<0.01$ 

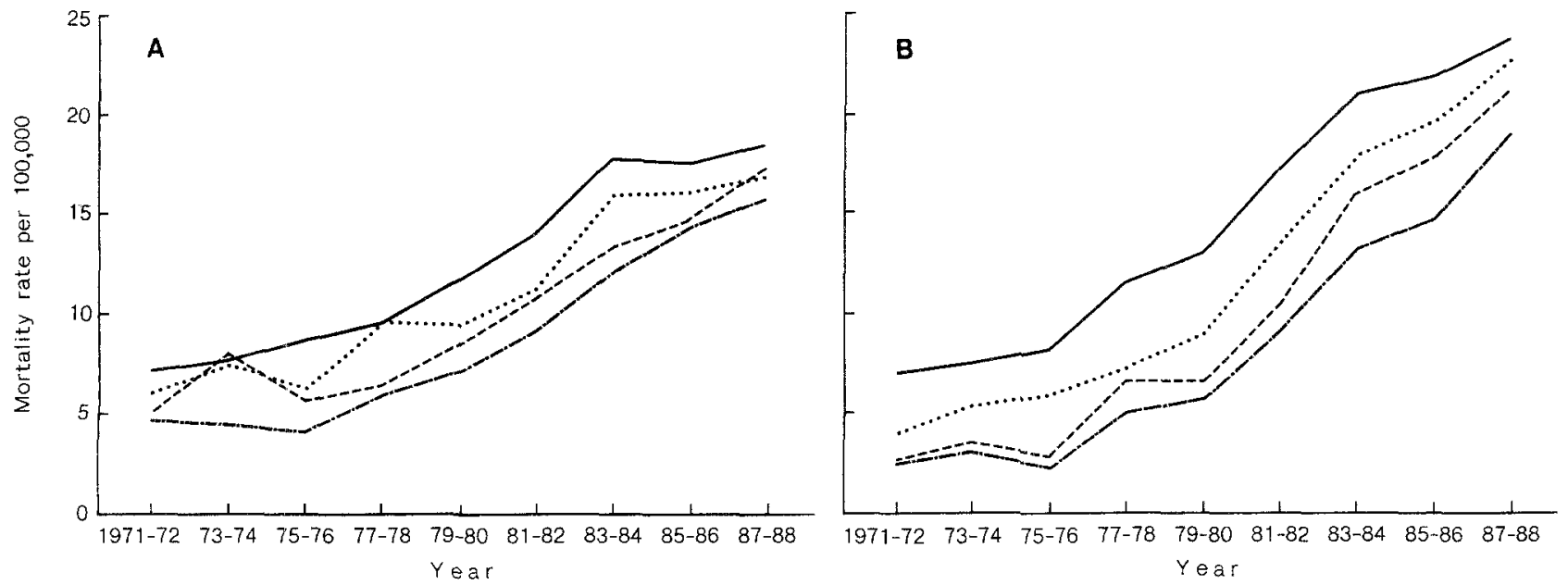

Fig. 7 A, B. Secular trends of diabetes mellitus mortality in Taiwan, 1971-1988 by urbanization and sex. A Male Metropolitan - City …., Town -.-, Rural -..... B Female Metropolitan -, City …., Town -- , Rural -...

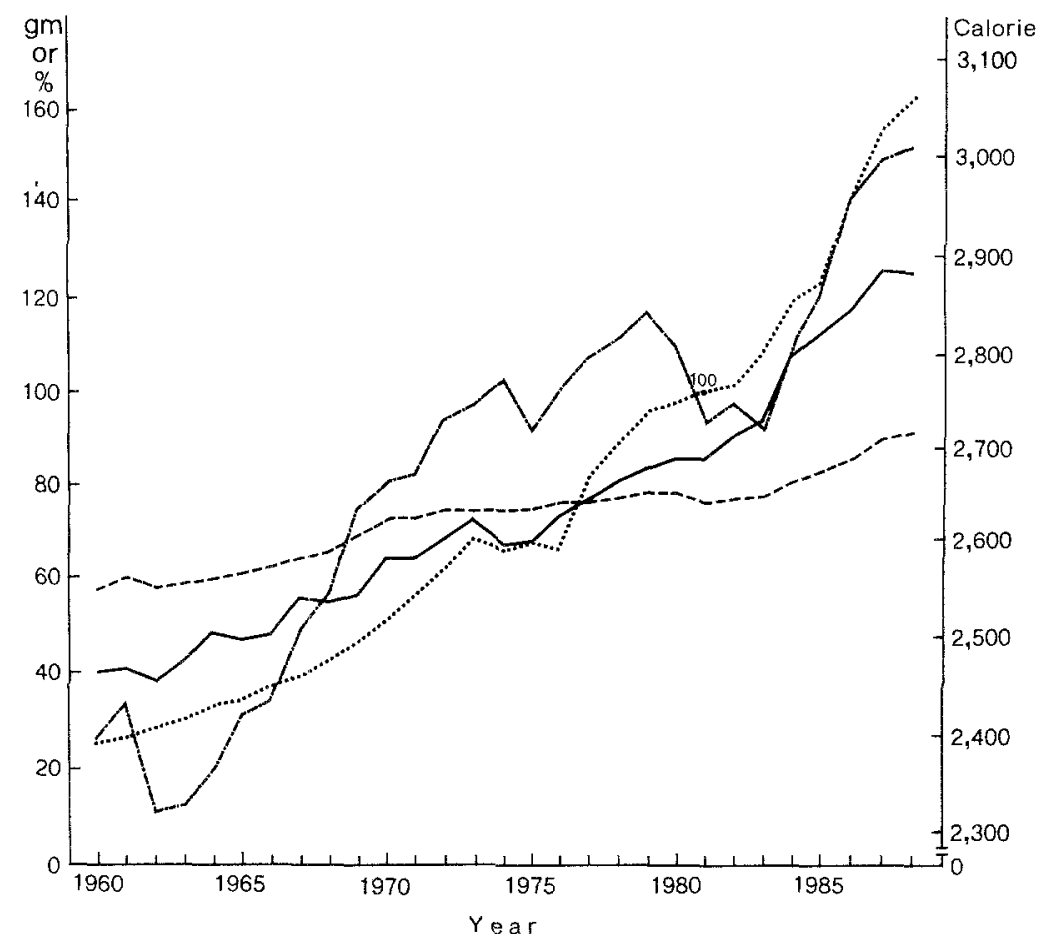

Fig. 8. Secular trends of per capita income, and of calorie, protein, and fat consumption in Taiwan, 1960-1988. Fat (g) -, Protein (g) ---, Calorie -...-, Income ..... Index year for per capita income is 1981 as 100 (US\$2,443) support our contention, showed that the age-adjusted prevalence rates for those aged 40 years or over in Taipei City were $5.05 \%, 7.10 \%, 8.17 \%$ for 1970,1979 , and 1986 , respectively [13]. As well as this, our analysis, which by means of the age-period-cohort model revealed that, in addition to age and period effects, birth-cohort effect also played a significant role in the trends, which might account for part of this phenomenon because the elderly represent an earlier generation when the risk of dying from diabetes increased in successive birth-cohorts, whereas the young live in a generation when rising trends have levelled off. Alternatively, the elderly who experienced or accumulated sufficient amounts of diabetic risk factors in their lifetime, and received additional triggers from the current affluent environment, would be most likely to develop the disease, and therefore, show the most conspicuous rising mortality trends. Increasing fat consumption and calorie intake as well as less physical activity associated with urbanization might account for the dramatic increase in diabetes mortality in Taiwan which deserves further study.

The significant birth-cohort effects for diabetes found in this study imply that some important determinants of the disease might occur early in life, but not show their effects until some time later. For example, vocational preferences, dietary habits and the nutritional status of a birth cohort may be determined in early life. But we must also consider possible generation-related reproductive experiences or age-specific exposures such as war, epidemics or lifestyle changes, which might enhance or be de- 
trimental to some developmental stages of diabetes. It is of interest to note after the 1910-1917 birth cohort a continuously declining risk in the recent birth cohorts for females. It raises a possible suggestion that environmental factors, regardless of what they were, had diminished the intensity in later birth cohorts for females but not for males. The declining parity of women is thought to be associated with this birth cohort effect for females as the general fertility rate in Taiwan has shown a declining trend after 1952. The present findings can also be compared to our previous study of pancreatic cancer [9] where mortality was shown to have increasing cohort effects up to the 1917-1926 birth-cohort and declined thereafter for both sexes. It is worthwhile, to further explore what, besides the reproductive factors, differentiates the patterns of cohort effects for diabetes between males and females and those between diabetes and pancreatic cancer in Taiwan.

Excess risk for diabetes in urban areas, repeatedly demonstrated in studies conducted in almost all parts of the world [14-16], a previous study in Taiwan [17], and again in this study seem consistent with the hypothesis of an urbanization factor in the aetiology of diabetes. Obesity [13, 18-20], physical activity [21-24], diet [25-27], psychosocial stress due to modernization $[28,29]$, and other variables [30-32] have been proposed as risk factors for diabetes which are associated with urbanization. However, other possible factors in an urban environment operating independently of the above remain to be explored.

While diabetic incidence studies demonstrate no clear evidence that gender influences the risk for the development of diabetes [31], high mortality rates in females have been repeatedly shown in mortality statistics from various countries $[33,34]$. This apparent paradox may be attributable to the higher fatality rate for female diabetic patients [33]. Using prevalence data, which may be confounded by the duration of disease, further complicates the aetiological inference. Therefore, a comprehensive model [35] with which to describe prevalence, mortality, and incidence of diabetes in the general population is clearly warranted.

Acknowledgements. The authors are indebted to Ms. H-WLin and Mr. S-CHung for their excellent secretarial assistance.

\section{References}

1. National diabetes data group (1983) Harris M, Hammon R (eds) Diabetes in America. NIH Pub. No. 85-1468. Government Printing Office, Washington

2. Taiwan Provincial Department of Health (1971-1988) Vital statistics. Chung-Hsin New Village, Provincial Department of Health, Taiwan, ROC

3.Tzeng GH, Wu TY (1986) Characteristics of urbanizational levels in Taiwan districts. Geograph Res 12: 287-323

4. Council for economic planning and development, ROC (1991) Taiwan statistical data book. Taipei, Taiwan. ROC

5.Breslow NE, Day NE (1987) Statistical methods in cancer research, vol. II. International Agency for Research on Cancer Scientific Publications, Lyon
6. Waterhouse RJ, Muir C, Correa P, Powell J (1976) Cancer incidence in five continents, vol III. International Agency for Research on Cancer Scientific Publications, Lyon

7. Robertson C, Boyle P (1986) Age, period, and cohort models: the use of individual records. Stat Med 5: 527-538

8. Statistics and epidemiology research corporation (1988) Egret user's manual, copyright 1985-1988. Washington

9. Lee WC, Lin RS (1990) Age-period-cohort analysis of pancreatic cancer mortality in Taiwan, 1971-1986. Int J Epidemiol 19: 839847

10. Palumbo PJ, Elveback LR, Chu CP, Connolly DC, Kurland LT (1976) Diabetes mellitus: incidence, prevalence, survivorship, and causes of death in Rochester, Minnesota 1945-1970. Diabetes 25: 566-569

11. Tokuhata GH, Miller W, Digon E, Hartnab T (1975) Diabetes mellitus: an underestimated public health problem. J Chron Dis 28: $23-35$

12. Fuller JH, Elford J, Goldblatt P, Adelstein AM (1983) Diabetes mortality: new light on an underestimated public health problem. Diabetologia 24:336-341

13. Tai TY, Yang CL, Chang CJ et al. (1987) Epidemiology of diabetes mellitus among adults in Taiwan, ROC. J Med Ass Thailand 70 [Suppl 2]: 42-48

14. Zimmet P, Taylor R, Ram P et al. (1983) Prevalence of diabetes and impaired glucose tolerance in the biracial (Melanesian and Indian) population of Fiji: a rural-urban comparison. Am J Epidemiol 118: 673-688

15. King H, Zimmet P, Raper LR, Baldau B (1984) Risk factors for diabetes in three Pacific populations. Am J Epidemiol 119: 396409

16. Papoz L, Khalifa B, Eschwege E, Ayed HB (1988) Diabetes mellitus in Tunisia: description in urban and rural populations. Int $J$ Epidemiol 17: 419-422

17. Tai TY, Yang CL, Chang CJ et al. (1987) Epidemiology of diabetes mellitus in Taiwan, ROC: comparison between urban and rural areas. J Med Ass Thailand 70 [Suppl 2]: 49-53

18. Knowler WC, Pettitt DJ, Savage PJ, Bennett PH (1981) Diabetes incidence in Pima Indians: contributions of obesity and parental diabetes. Am I Epidemiol 113: 144-156

19. Ohlson LO, Larsson B, Svardsudd K et al. (1985) The influence of body fat distribution on the incidence of diabetes mellitus: 13.5 years of follow up of the participants in the study of men born in 1913. Diabetes 34: 1055-1058

20. Modan M, Karasik A, Halkin H et al. (1986) Effect of past and concurrent body mass index on prevalence of glucose intolerance and type 2 (non-insulin-dependent) diabetes and on insulin response: the Israel study of glucose intolerance, obesity and hypertension. Diabetologia 29: 82-89

21. Lipman RL, Raskin P, Love T et al. (1972) Glucose intolerance during decreased physical activity in man. Diabetes $21: 101-107$

22. Bogardus C, Ravussin E, Robbins DC, Wolfe RR, Horton ES, Sims EAH (1984) Effects of physical training and diet therapy on carbohydrate metabolism in patients with glucose intolerance and non-insulin-dependent diabetes mellitus. Diabetes 33: 311318

23. Taylor R, Ram P, Zimmet P, Raper LR, Ringrose H (1984) Physical activity and prevalence of diabetes in Melanesian and Indian men in Fiji. Diabetologia 27: 578-582

24. Frisch RE, Wyshak G, Albright TE, Albright NL, Schiff I (1986) Lower prevalence of diabetes in female former college athletes compared with nonathletes. Diabetes 35: 1101-1105

25. Trowell H (1975) Dietary-fiber hypothesis of the etiology of diabetes mellitus. Diabetes 24: 762-765

26. West KM (1978) Epidemiology of diabetes and its vascular complications. Elsevier, New York

27. Kawate R, Yamakido M, Nishimoto Y.(1979) Diabetes mellitus and its complications in Japanese migrants on the island of Hawaii. Diabetes Care 2: 161-170

28. Porte D Jr, Berthoud HR, Jeanrenaud B, Woods SC (1981) Diabetes and the nervous system. Diabetologia 20 [Suppl]: 305313 
29. Taylor R, Zimmet P (1983) Migrant studies in diabetes epidemiology. In: Mann JI, Pyorala K, Teuscher A (eds): Diabetes in epidemiological perspective. Churchill Livingstone

30.Zimmet P (1982) Type 2 (non-insulin-dependent) diabetes - an epidemiological overview. Diabetologia 22:399-411

31. Nelson RG, Everhart JE, Knowler WC, Bennett PH (1988) Incidence, prevalence and risk factors for non-insulin-dependent diabetes mellitus. Primary Care 15:227-250

32. Taylor R (1989) Aetiology of non-insulin dependent diabetes. $\mathrm{Br}$ Med Bull 45: 73-91

33. Hamman RF (1983) Diabetes in affluent societies. In: Mann JI, Pyorala K, Teuscher A (eds) Diabetes in epidemiological perspective. Churchill Livingstone

34. Entmacher PS, Krall LP, Kranczer SN (1985) Diabetes mortality from vital statistics. In: Marble A, Krall LP, Bradley RF, Christlieb AR, Soeldner JS (eds) Joslin's diabetes mellitus, 12th ed. Lea \& Febiger, Philadelphia
35. Herman WH, Sinnock P, Brenner E (1984) An epidemiologic model for diabetes mellitus: incidence, prevalence, and mortality. Diabetes Care 7: 367-371

Received: 10 April 1992

and in revised form: 10 June 1992

Dr. R.S. Lin

Institute of Public Health

College of Medicine

National Taiwan University

1 Jen-Ai Rd. 1st Sec.

Taipei

Taiwan

ROC 